\title{
Pelatihan Jaringan Digital Marketing Sebagai Sarana Penunjang Pemasaran Produk UMKM di Desa Sukopuro, Jabung, Kabupaten Malang Jawa Timur
}

\author{
Tri Kristianti ${ }^{1}$, Wirawan Aryanto Balol ${ }^{2}$, Peni Puspitasari ${ }^{3 *}$ \\ 1,2,3 Prodi Teknik Industri, Fakultas Teknik, Universitas Wisnuwardhana Malang, Jalan Terusan \\ Danau Sentani No.99, Malang, Provinsi Jawa Timur, Indonesia.
}

Author's Email: trikristianti@wisnuwardhana.ac.id 1, wirawan@wisnuwardhana.ac.id 2, Corresponding Email: penipuspitasari@wisnuwardhana.ac.id ${ }^{3}$.

\section{Article History:}

Received: Nov 23th 2021

Revised: Nov 29th 2021

Accepted: Dec 8th 2021

Published: Jan 1th 2022

Keywords: Product

Marketing; MSME's; Digital

Marketing; Unidha KKn

Malang.
Abstract: Sukopuro Village has around a hundred MSME actors with processed local agricultural products which are dominated by cassava. The COVID-19 pandemic has reduced the number of orders for MSME products in Sukopuro Village. One of the factors causing delays in product marketing is the limited knowledge of MSME actors on how to sell boldly (online). This training aims to provide insight as well as the practice of creating a digital marketing network in order to increase the marketing of MSME products in Sukopuro Village, Jabung District, Malang Regency, East Java. This training is carried out in the following stages; 1) data collection by direct observation and observation, 2) preparation of counseling consisting of requests for permits to village officials, preparation of training materials and media used, 3) implementation of counseling by the process of providing material through offline media, 4) activity evaluation. The results of this counseling are aimed at helping participants who do not understand marketing strategies boldly (online) to understand how to have an email account and social media to be used as a means to market their MSME products. 


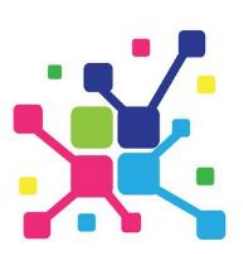

\section{Pendahuluan}

Kegiatan Kuliah Kerja Nyata (KKN) merupakan bagian dari agenda tahunan yang diselenggarakan oleh Universitas Wisnuwardhana menurut Pedoman Pelaksanaan KKN di Perguruan Tinggi yakni sekitar 3-4 SKS demi menunjang keterampilan mahasiswa [1] dalam hidup bermasyarakat [2]. Tujuan dari kegiatan KKN ini adalah agar mahasiswa belajar menjadi seorang problem solver sehingga kegiatan desa dilakukan dan direncanakan oleh mahasiswa sendiri dengan bantuan moral dan dukungan penuh dari Tim Panitia KKN, Dosen Pembimbing Lapangan (DPL), Perangkat Desa, Tokoh Masyarakat, Organisasi Masyarakat dan Dinas/Instansi terkait. Kegiatan ini juga melatih mahasiswa agar lebih siap dalam menghadapi segala persoalan dalam kehidupan bermasyarakat, sehingga diharapkan Ketika mereka lulus dapat menerapkan ilmu yang telah diperoleh selama kegiatan KKN berlangsung. Dengan tujuan tersebut, maka kegiatan KKN ini dilaksanakan dengan tidak memberi batasan pada mahasiswa dengan bidang studi tertentu agar mahasiswa bebas untuk mencoba memecahkan semua problema yang dihadapi di desa tempat mereka menjalani KKN, apapun juga bidang studi yang sedang mereka tempuh.

Sehubungan dengan pandemi COVID 19 yang belum berakhir, maka kegiatan KKN yang semula berlangsung selama 2 (dua) bulan dan mewajibkan mahasiswa untuk menginap, maka di tahun ini diberikan peraturan yang tidak bersifat mengikat namun tetap sesuai Protokol Kesehatan (prokes) sehingga terlaksana KKN secara kondusif. Secara kronologis aktivitas KKN Universitas Wisnuwardhana Malang diawali dengan observasi pendahuluan oleh Tim Panitia KKN dan Dosen Pembimbing Lapangan (DPL) untuk mengidentifikasi masalah, potensi dan kebutuhan pembangunan yang dirasakan masyarakat saat ini kemudian dirumuskan menjadi suatu program kerja. Program kerja tersebut sebelum dilaksakan, dibahas terlebih dahulu dengan aparat desa, masyarakat desa, dan lembaga organisasi masyarakat desa serta dinas/instansi dari tingkat kecamatan untuk mendefinitifkan program kerja tersebut agar tercapai sudut pandang yang sama dan sesuai dengan kebutuhan desa. Sedangkan mahasiswa berperan sebagai komunikator yang artinya memindahkan semua idea dan keinginan kepada pihak lain demi kebaikan bersama. Mar'at (1984:36) mengatakan jika ide ini diterima dan ada keyakinan dalam dirinya atas kebenaran ide ini maka secara sadar akan timbul perubahan sikap yang artinya menguasai pengetahuan, segala bentuk ketrampilan yang dibutuhkan oleh masyarakat, bersikap terbuka terhadap pelaksanaan KKN dan memiliki minat serta kesungguhan dalam melaksanakan kegiatan di lapangan serta melakukan pendekatan sosial agar mendapat respons yang positif dari masyarakat [3].

Surya Anwar (1983:5) menyebutkan jika kualitas mahasiswa yang ber-KKN sangat berpengaruh terhadap dampak KKN, kualitas mahasiswa tersebut dapat dilihat dari penguasaan pengetahuan, ketrampilan, yang dibutuhkan masyarakat agar bersikap positif terhadap pelaksanaan KKN [4]. Salah satu lokasi KKN yang ditetapkan oleh Universitas Wisnuwardhana Malang adalah Desa Sukopuro, Kecamatan Jabung, 


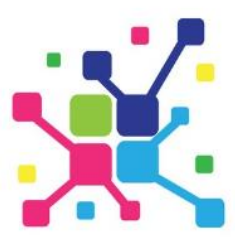

Kabupaten Malang dan bermitra dengan pemilik UMKM di Sukopuro. Selama berada di lokasi KKN, para Dosen Pembimbing Lapangan (DPL) meninjau bahwa ada beberapa permasalahan yang terjadi sebagai berikut.

1) Penurunan jumlah pemasukan pesanan selama pandemi COVID 19.

2) Kesulitan pemasaran karena terbatasnya pengetahuan tentang penjualan secara daring (online) oleh para pelaku UMKM

Andreas Kaplan dan Michael Haenlein dalam artikelnya berjudul "Users of the world, unite! The challenges and opportunities of Social Media," di Majalah Business Horizons (2010) halaman 59-68 mendefinisikan media sosial sebagai "sebuah kelompok aplikasi berbasis internet yang dibangun di atas dasar ideologi dan teknologi Web 2.0 dan memungkinkan penciptaan dan pertukaran user-generated content" [5]. Lebih lanjut di artikel yang sama, Andreas M Kaplan dan Michael Haenlein juga membuat klasifikasi untuk berbagai jenis media sosial yang ada berdasarkan ciri-ciri penggunaannya. Menurut mereka, pada dasarnya media sosial dapat dibagi menjadi enam jenis, yaitu:

a. Proyek kolaborasi website, di mana penggunanya diizinkan untuk dapat mengubah, menambah, atau pun membuang konten-konten yang termuat di website tersebut, seperti Wikipedia.

b. Blog dan microblog, di mana user mendapat kebebasan dalam mengungkapkan suatu hal di blog itu, seperti perasaan, pengalaman, pernyataan, sampai kritikan terhadap suatu hal, seperti Twitter.

c. Konten atau isi, di mana para user di website ini saling membagikan konten-konten multimedia, seperti e-book, video, foto, gambar, dan lain-lain seperti Youtube.

d. Situs jejaring sosial, di mana user memperoleh izin untuk terkoneksi dengan cara membuat informasi yang bersifat pribadi, kelompok atau sosial sehingga dapat terhubung atau diakses oleh orang lain, seperti misalnya Facebook.

e. Virtual game world, di mana pengguna melalui aplikasi 3D dapat muncul dalam wujud avatar-avatar sesuai keinginan dan kemudian berinteraksi dengan orang lain yang mengambil wujud avatar juga layaknya di dunia nyata, seperti online game.

f. Virtual social world, merupakan aplikasi berwujud dunia virtual yang memberi kesempatan pada penggunanya berada dan hidup di dunia virtual untuk berinteraksi dengan yang lain. Virtual social world ini tidak jauh berbeda dengan virtual game world, namun lebih bebas terkait dengan berbagai aspek kehidupan, seperti Second Life [4].

Menurut Huston dan Brigham (2006:39) berpendapat bahwa perusahaan dengan penjualan yang relatif stabil dapat lebih aman memperoleh lebih banyak pinjaman dan menangung beban tetap yang lebih tinggi dibandingkan dengan perusahaan dengan penjualannya yang tidak stabil [6]. Swastha dan Handoko (2001) mengatakan bahwa pertumbuhan atas penjualan merupakan indikator penting dari penerimaan pasar dari produk dan atau jasa perusahaan tersebut, dimana pendapatan yang dihasilkan dari 
penjualan akan dapat digunakan untuk mengukur tingkat pertumbuhan penjualan. Berkaitan dengan pertumbuhan penjualan, perusahaan harus mempunyai strategi yang tepat agar dapat memenangkan pasar dengan menarik konsumen agar selalu memilih produknya [7]. Untuk itu faktor-faktor yang mempengaruhi penjualan harus benar-benar diperhatikan.dengan mengetahui faktor-faktor tersebut perusahaan akan dapat menetapkan kebijaksanaan untuk mengantisipasi kondisi tersebut sehingga perusahaan dapat menjual produk dalam jumlah besar dan volume penjualan akan meningkat pula. Dengan meningkatnya laba perusahaan, maka keuntungan yang diperoleh para investor akan meningkat. Pertumbuhan penjualan mencerminkan keberhasilan investasi periode masa lalu dan dapat dijadikan sebagai prediksi pertumbuhan masa yang akan dating [8].

Sehubungan dengan teori yang telah dipaparkan tersebut di atas dan berdasarkan hasil dari pengamatan secara langsung, maka Dosen Pembimbing Lapangan (DPL) bermaksud untuk memberikan solusi dari permasalahan dan kendala yang telah disesuaikan dengan kapasitas pengetahuan dan kemampuan masyarakat desa pemilik UMKM dengan menyelenggarakan kegiatan penyuluhan/ sosialisasi digital marketing bagi para pelaku UKMK di daerah desa Sukopuro, Jabung, Kabupaten Malang Jawa Timur. Adapun manfaat yang dapat diperoleh dengan terselenggaranya pelatihan ini sebagai berikut.

1) Memberikan kesempatan pelatihan (workshop) praktik secara langsung di lokasi penggunaan media penjualan secara daring.

2) Memberikan solusi (tips dan trick) cara menaikkan popularitas toko online.

\section{Metode}

a. Metode Pelaksanaan Kegiatan

Metode yang digunakan untuk membantu mitra adalah dengan memberikan pelatihan ketrampilan, melakukan praktik secara langsung, serta pendampingan secara berkelanjutan. Pelatihan diikuti oleh 20 perwakilan mitra pemilik UMKM di Desa Sukopuro. Untuk mendukung pelaksanaan pada program, sebelumnya telah disusun beberapa rencana kegiatan diantaranya sebagai berikut:

1) Melakukan persiapan dengan menjalin kerjasama dengan perangkat desa dan mitra;

2) Menyiapkan fasilitas operasional serta materi pembelajaran dan praktik;

3) Menyediakan fasilitas pendukung yang dibutuhkan untuk penyuluhan.

Metode yang digunakan untuk melaksanakan kegiatan adalah metode interaktif aplikatif yang melibatkan peserta seaktif mungkin dalam keseluruhan kegiatan pelatihan. Selama materi dipaparkan, peserta juga melakukan praktik sederhana pembuatan email dan akun media sosial dengan bantuan para Dosen Pembimbing Lapangan (DPL).

\section{b. Waktu Efektif Pelaksanaan Kegiatan}

Pelaksanaan kegiatan pendampingan dan pelatihan dilaksanakan selama sehari mulai pukul 12.00-14.00 pada hari sabtu tanggal 20 Maret 2021. 


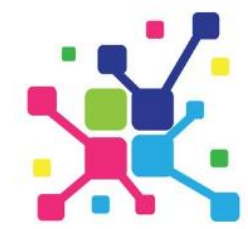

c. Tempat Kegiatan

Pelaksanaan Kegiatan di Balai Desa Sukopuro Jl. Pahlawan No.44, Dusun Luring, Sukopuro, Jabung, Malang, Jawa Timur 65155.

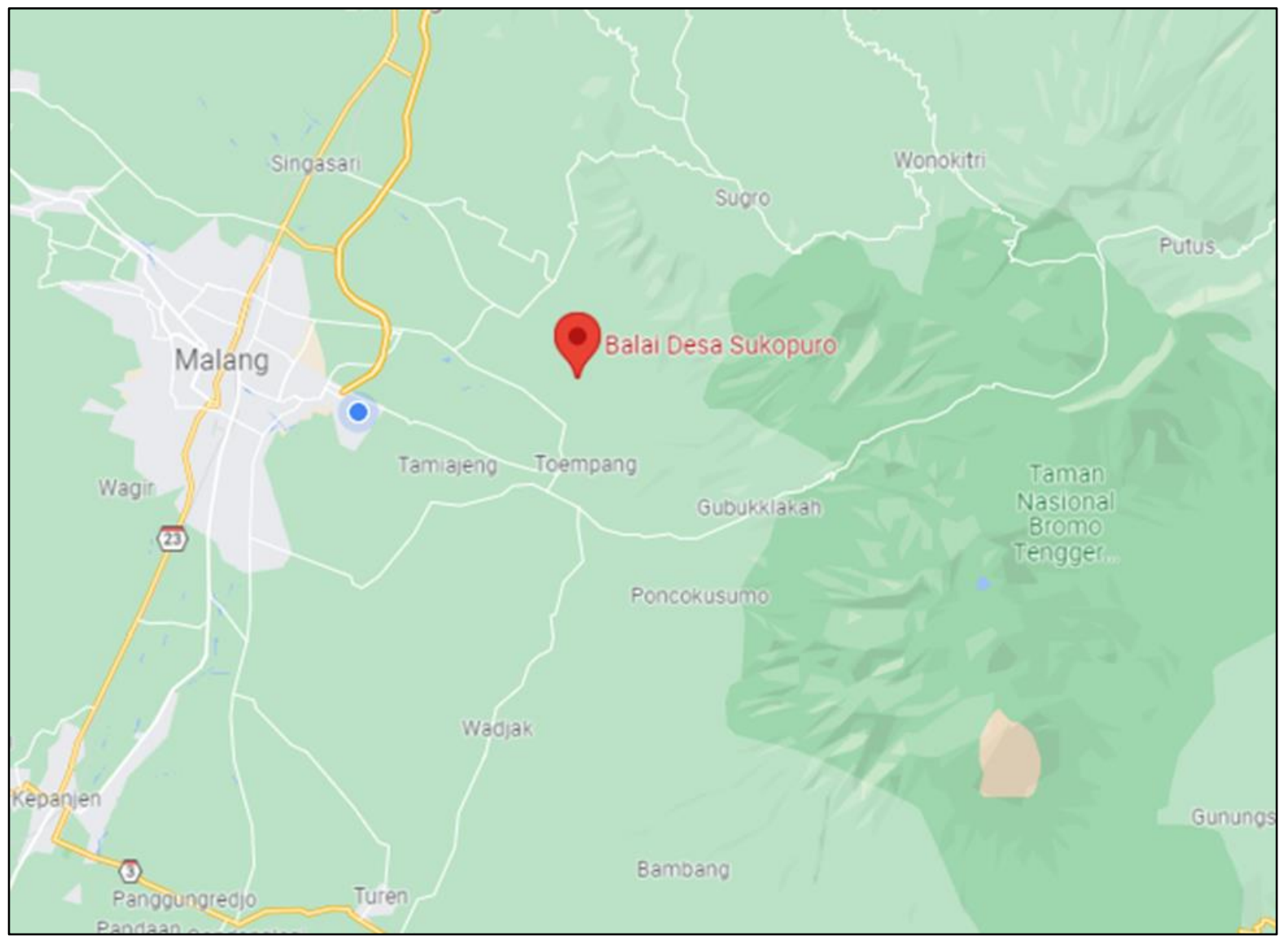

Gambar 1. Map Lokasi Kegiatan

\section{Hasil}

Pada saat pelaksanaan kegiatan terlihat antusias peserta yang tinggi dan tim DPL merasa pelatihan ini sangat bermanfaat dan dibutuhkan oleh masyarakat. Masyarakat yang masih awam terhadap pemasaran digital sangat terbantu dengan adanya pelatihan ini, karena di era seperti ini pemasaran dengan menggunakan metode digital mutlak tidak bisa dihindari jika tidak ingin tertinggal.

Kegiatan ini juga membuat peserta yang semula tidak memiliki akun email dan media sosial menjadi memiliki email dan media sossial sehingga dapat digunakan sebagai sarana dalam memasarkan produk UMKM yang mereka miliki. Hasil dan pembahasan dalam penyuluhan di Desa Sukopuro ini akan dijelaskan berdasarkan tahapan-tahapan berikut. Tahapan-tahapan tersebut dilakukan dengan tetap mengedepankan protokol kesehatan dalam rangka menekan penularan Covid 19.

1) Tahap Persiapan

Pada tahap ini, kegiatan dimulai dengan (1) pengumpulan data dengan observasi dan 


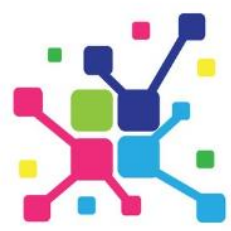

A J A D

Jurnal Pengabdian kepada Masyarakat

Vol. 2, No. 1, May, 2022, pp. 21-28

DOI : https://doi.org/10.35870/ajad.v2i1.26

pengamatan langsung; (2) persiapan penyuluhan yang terdiri atas permohonan izin pada perangkat desa, persiapan materi dan media pelatihan yang digunakan menyesuaikan kegiataan dengan jadwal kegiatan di Sukopuro; (3) merencanakan sasaran perwakilan mitra dalam penyuluhan.
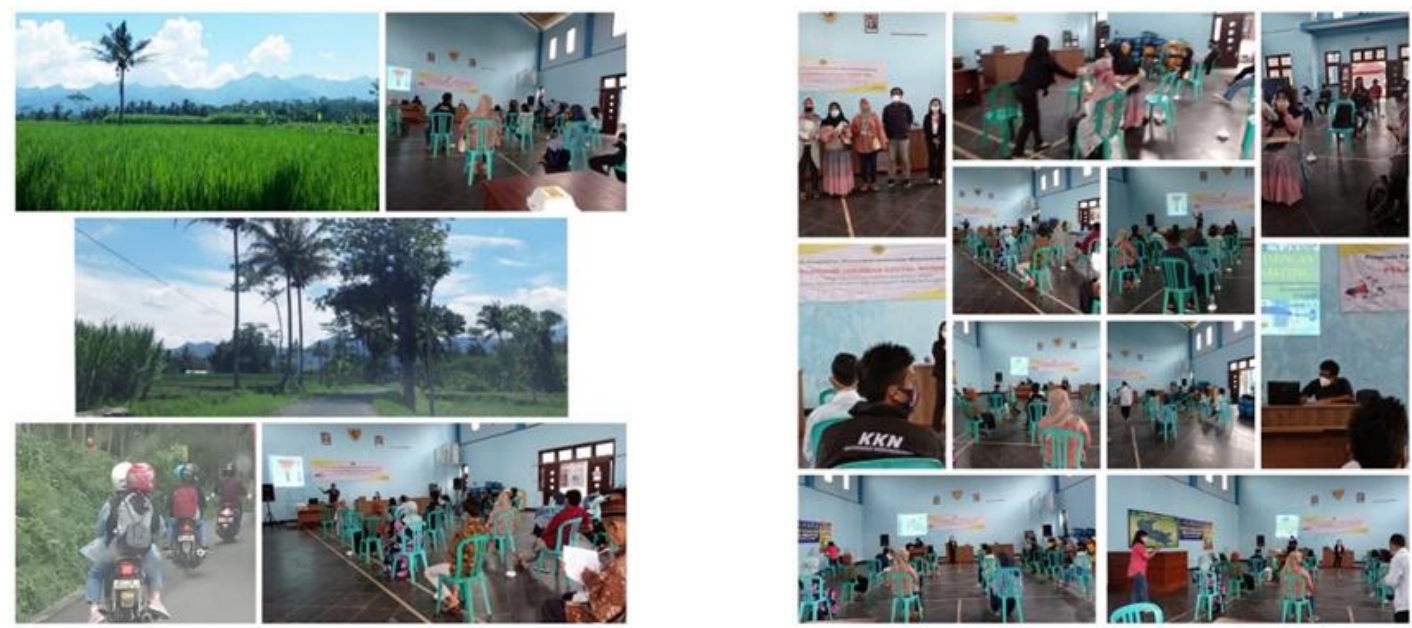

Gambar 2. Tahap Persiapan

2) Tahap Pelaksanaan

Setelah tahap persiapan dinilai telah sesuai dengan program penyuluhan, tahap selanjutnya adalah tahap kegiatan. Hal yang utama dari tahap kegiatan ini adalah penyampaian materi tentang pentingnya jaringan digital marketing sebagai sarana penunjang pemasaran produk UMKM, contoh konkret penggunaan digital marketing sebagai sarana pemasaran produk, dan praktik sederhana pembuatan jaringan digital marketing oleh masing-masing mitra.
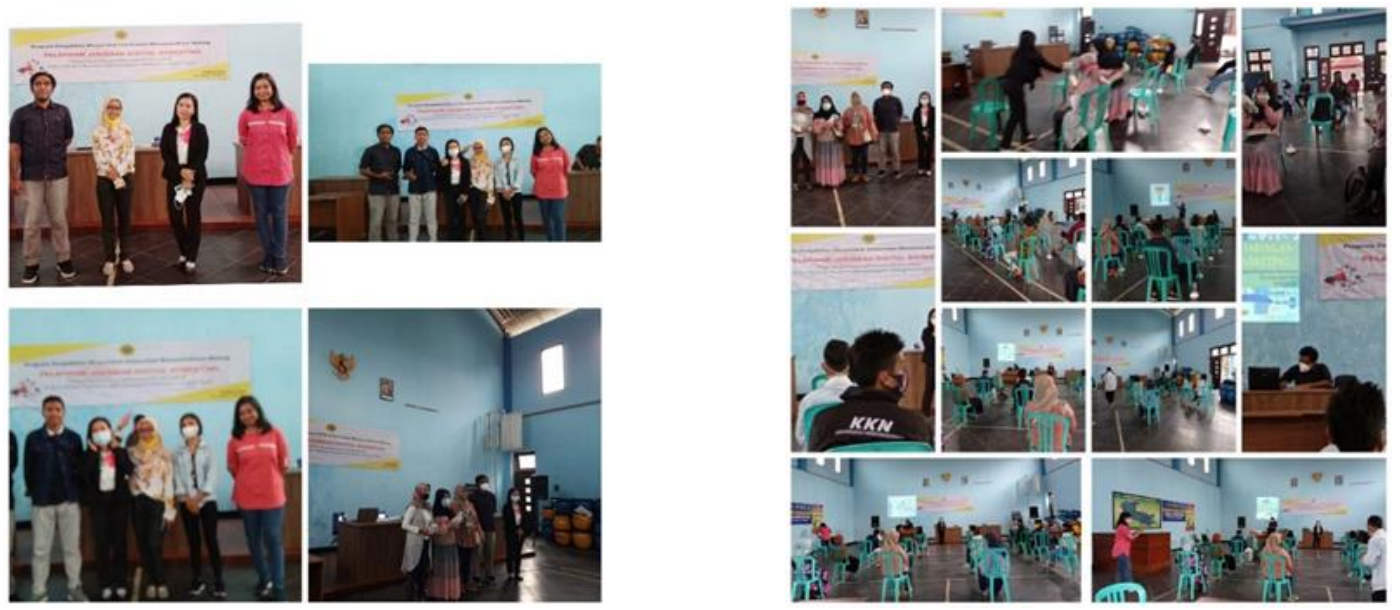

Gambar 3. Tahap Pelaksanaan

3) Tahap Evaluasi

Tahap ketiga pada kegiatan penyuluhan ini adalah tahap evaluasi kegiatan. Berdasarkan kegiatan ini, muncul beberapa dampak yang harus dibenahi terkait kegiatan penyuluhan pemanfaatan jaringan digital marketing agar menjadi pedoman dalam pelaksanaan kegiatan serupa di masa mendatang. Hal-hal yang perlu diperhatikan adalah sebagai berikut; 


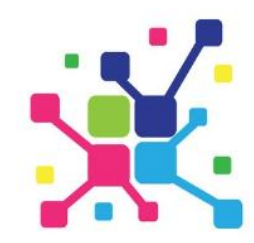

1. Penggunaan media sebagai pendukung kegiatan penyuluhan seperti; mic, speaker dan LCD sebaiknya disiapkan dan diperiksa terlebih dahulu guna menghindari kesalahan teknis selama kegiatan berlangsung.

2. Kegiatan serupa sebaiknya dilaksanakan secara berkesinambungan agar masyarakat pemilik UMKM mendapatkan tambahan ilmu pengetahuan tentang strategi penjualan secara daring yang lebih mumpuni sehingga dapat membantu menaikkan omset penjualan mereka.

\subsection{Masyarakat Sasaran}

Sasaran dari kegiatan ini adalah masyarakat Pemilik UMKM di Desa Sukopuro, Kecamatan Jabung, Kabupaten Malang yang mengalami penurunan penjualan produk terdampak Pandemi Covid 19.

\section{Kesimpulan}

Pada saat pelaksanaan kegiatan terlihat antusias peserta yang tinggi dan tim merasa pelatihan ini sangat bermanfaat dan dibutuhkan oleh masyarakat. Masyarakat yang masih awam terhadap pemasaran digital sangat terbantu dengan adanya pelatihan ini, karena di era seperti ini pemasaran dengan menggunakan metode digital mutlak tidak bisa dihindari jika tidak ingin tertinggal.

Dengan demikian, kegiatan penyuluhan yang diadakan di Desa Sukopuro ini menjadi kunci dalam memupuk kesadaran mitra akan pentingnya pemanfaatan jaringan digital marketing sebagai sarana penunjang pemasaran produk UMKM. Selain itu, penggunaan media sosial sebagai salah satu cara penjualan produk UMKM akan memudahkan para pemilik UMKM karena dapat menghemat waktu dan biaya operasional. Oleh sebab itu, diharapkan hasil dari penyuluhan ini dapat bermanfaat bagi masyarakat umum pelaku UMKM terutama masyarakat desa Desa Sukopuro, Kecamatan Jabung, Kabupaten Malang Jawa Timur.

\section{Daftar Referensi}

[1] Lembaga Penelitian dan Pengabdian Kepada Masyarakat (LPPM) Universitas Wisnuwardhana Malang. 2019. Buku Pedoman Kuliah Kerja Nyata (KKN) UniversitasWisnuwardhana Malang Th. Akademik 2019-2020. Universitas Wisnuwardhana Malang.

[2] Departemen Pendidikan dan Kebudayaan, Direktorat Penelitian dan Pengabdian kepada Masyarakat (P3M), 1983. Pedoman Pelaksanaan Kuliah Kerja Nyata (KKN) di Perguruan Tinggi, Edisi 3.

[3] Mar'at, 1981. Sikap Manusia Perubahan serta Pengukurannya, Psikologi UNPAD Bandung, Ghalia Indonesia. 
[4] Anwar, Surya, 1982. Dampak Kuliah Kerja Nyata (KKN) pada Masyarakat Desa. Kasus KKN UNDIP di Sumatra Barat. (Disertasi)

[5] Kaplan, Andreas M.; Michael Haenlein (2010) "Users of the world, unite! The challenges and opportunities of Social Media". Business Horizons 53(1): 59-68.

[6] Brigham, Eugene F dan Houston. 2006. Fundamental of Financial Management: Dasar-Dasar Manajemen Keuangan. Edisi 10. Jakarta: Salemba Empat.

[7] Basu Swastha, T. Hani Handoko, 2001. Manajemen Pemasaran Analisis Perilaku Konsumen , Edisi2, Liberty. Yogyakarta.

[8] Barton, Sidney L.,Ned C.Hill, and Sirinivasan Sundaran, (1989). An Empirical Test of Stakeholder Theory Predictions of Capital Structure, Journal of the Financial Management Association, Spring. 